\title{
KAJIAN SUMBER ENERGI PADA PENGOLAHAN KELAPA SAWIT MENJADI CRUDE PALM OIL (CPO) DI PT. ALNO AGRO UTAMA SUMINDO OIL MILL, BENGKULU UTARA
}

\author{
THE STUDY OF ENERGY SOURCES ON CRUDE PALM OIL (CPO) BEING \\ PROCESSED PALM OIL AT PT. ALNO AGRO UTAMA SUMINDO OIL MILL, \\ NORTH BENGKULU
}

\author{
Lukman Hidayat ${ }^{1}$, Fitri Electrika Dewi Surawan ${ }^{1}$, Arga Harianda Lumban Raja ${ }^{2}$ \\ ${ }^{1}$ Staf Pengajar Jurusan Teknologi Pertanian Fakultas Pertanian, Universitas Bengkulu \\ ${ }^{2}$ Alumni Program Studi Teknologi Industri Pertanian, Jurusan Teknologi Pertanian Fakultas \\ Pertanian, Universitas Bengkulu \\ e-mail: lukman_hidayat@unib.ac.id
}

\begin{abstract}
Increasing demand for Crude Palm Oil (CPO) as the vegetable oil was causing the industry to cultivate palm oil increased, so that the energy required to produce $\mathrm{CPO}$ also increased. The purpose of this study is to identify the type, source and calculate the amount of energy needs, calculate the level of efficiency and energy savings opportunities. Stages of the research are initial energy analysis, a detailed energy, and energy analysis in processing systems. Based on the research results, to produce each $\mathrm{kg}$ of CPO processing capacity of 60 ton TBS / hour with a recovery rate of $20.59 \%$ of primary energy needs of $16.200679 \mathrm{MJ} / \mathrm{kg}$. Real boiler efficiency of $45.69 \%$, the real efficiency of the turbine was $94,86 \%$. Turbine efficiency to generate electrical energy by $1.09 \%$, the technical efficiency of $66.80 \%$ turbines, diesel generators technical efficiency of $47.25 \%$, the technical efficiency of electric motors by $59.37 \%$. The total efficiency of electricity use by $4,75 \%$, the efficiency of diesel estate of $1.379 \%$ and the efficiency of the use of steam at $93.77 \%$. Energy can be saved by $0.0442 \mathrm{MJ} / \mathrm{kg}$ with a description of human powered energy of $0.0004316 \mathrm{MJ} / \mathrm{kg}$, energy electrical energy by $.04372 \mathrm{MJ} / \mathrm{kg}$. While energy can be stored on the excess energy to fuel biomass boiler was $1.45 \mathrm{MJ} / \mathrm{kg}$
\end{abstract}

Keyword : Crude Palm Oil, Energy Analysis, Energy Efficiency

\begin{abstract}
ABSTRAK
Peningkatan kebutuhan Crude Palm Oil (CPO) sebagai minyak nabati berdampak pada peningkatan industri pengolahan kelapa sawit, sehingga energi yang dibutuhkan untuk memproduksi $C P O$ juga ikut meningkat. Penelitian ini bertujuan untuk mengidentifikasi jenis, sumber dan menghitung jumlah kebutuhan energi, menghitung tingkat efisiensi dan peluang penghematan energi. Tahapan penelitian yang dilakukan yaitu analisis energi awal, energi rinci, energi pada sistem pengolahan. Berdasarkan hasil penelitian, untuk memproduksi tiap $\mathrm{kg} C P O$ pada kapasitas pengolahan 60 ton TBS/jam dengan tingkat rendemen 20,59\% dibutuhkan energi primer sebesar 16,200679 MJ/kg. Efisiensi real boiler sebesar 45,69\%, efisiensi real turbin sebesar $94,86 \%$. Efisiensi turbin dalam menghasilkan energi listrik sebesar 1,09\%, efisiensi teknis turbin sebesar $66,80 \%$, efisiensi teknis generator diesel sebesar $47,25 \%$, efisiensi teknis motor listrik sebesar 59,37\%. Efisiensi total penggunaan listrik sebesar 49,75\%, efisiensi real diesel sebesar 1,379\% dan efisiensi penggunaan uap sebesar 93,77\%. Energi yang dapat dihemat sebesar $0,0442 \mathrm{MJ} / \mathrm{kg}$ dengan uraian energi tenaga manusia sebesar $0,0004316 \mathrm{MJ} / \mathrm{kg}$, energi energi listrik sebesar $0,04372 \mathrm{MJ} / \mathrm{kg}$. Sedangkan energi yang dapat disimpan dari kelebihan energi biomassa untuk bahan bakar boiler adalah 1,45 MJ/kg.
\end{abstract}

Kata Kunci : Crude Palm Oil, Analisis Energi, Efisiensi energi 


\section{PENDAHULUAN}

Tanaman kelapa sawit (Elaeis guineensis Jacq) adalah salah satu dari beberapa famili Aracacea dimana dahulu disebut sebagai Palmae. Tanaman kelapa sawit merupakan salah satu komoditi agroindustri unggulan Indonesia sekaligus penghasil minyak nabati dengan produktivitas yang lebih tinggi dibandingkan komoditi lainnya. Menurut Badan Pusat Statistik tahun 2013, peningkatan jumlah produksi $C P O$ di Indonesia dari tahun 2005 sampai 2011 selalu meningkat.

Meningkatnya permintaan terhadap minyak sawit atau Crude Palm Oil (CPO) mengakibatkan jumlah perusahaan kelapa sawit juga bertambah. Pada tahun 2014, jumlahnya 1601 perusahaan. Persebaran menurut pulau, yaitu: 63\% di Pulau Sumatera, $33 \%$ di Pulau Kalimantan, sisanya berada di Pulau Sulawesi, Jawa, Maluku, dan Papua. Jumlah perusahaan perkebunan terbanyak berada di Provinsi Sumatera Utara s332 perusahaan dan Provinsi Riau 192 perusahaan (Badan Pusat Statistik, 2014).

Menurut Fadly (2003) dan Wibowo (2008), meningkatnya Industri pengolahan kelapa sawit mengakibatkan energi yang dibutuhkan untuk memproduksi $C P O$ juga meningkat. Terbatasnya sumber energi tentunya membutuhkan antisipasi yang tepat agar tercapai penggunaan energi yang efektif dan efisien. Perhitungan mengenai pengadaan dan penggunaan energi dalam proses produksi perlu dilakukan, karena penggunaan energi akan berbanding lurus dengan biaya produksi. Penggunaan energi secara efektif dan efisien akan mampu menekan besarnya biaya produksi. Salah satu alternatif yang dapat dilakukan untuk mengetahui pola penggunaan energi pada proses energi yaitu melakukan kajian dengan cara analisis kebutuhan energi.

Analisis energi adalah perhitungan jumlah dan aliran energi pada suatu proses produksi atau aktivitas. Audit yang dilakukan memerlukan seluruh rangkaian proses yang bertujuan untuk mengevaluasi penggunaan energi yang dapat dihemat dari suatu aktivitas dan untuk mengidentifikasi peluang konservasi energi (Internasional Energy Agency, 1987)

\section{METODE PENELITIAN}

Penelitian ini dilaksanakan di PMKS PT. Alno Agro Utama Sumindo Oil Mill, Bengkulu Utara pada bulan Juni 2016 sampai bulan Juli 2016. Metode pengambilan data dengan dua cara yaitu, pengamblan data primer yang melakukan pengamatan langsung kebutuhan energi berupa input energi biomassa, energi minyak diesel (solar), energi manusia, energi listrik dan energi uap pada setiap tahapan pengolahan dan sarana pendukung. Pengambilan data sekunder dengan melihat buku laporan harian pabrik dan melakukan pencatatan data terkait darinya.

Tahapan penelitian yang dilakukan adalah penentuan batasan sistem, analisis energi awal, analisis energi rinci, analisis energi pada sistem produksi. Analisis data yang digunakan adalah analisis proses dalam skala mikro. Data yang diperoleh dimasukkan ke dalam persamaan yang telah ditentukan, sehingga diperoleh nilai kebutuhan energi pada tiap tahapan proses produksi. Kebutuhan total energi untuk menghasilkan tiap kg CPO merupakan jumlah kebutuhan energi pada tiap tahapan pengolahan. Analisis selanjutnya yaitu melihat efisiensi alat dan proses pada tiap tahapan produksi, sehingga dapat diketahui besarnya energi yang dapat dihemat. Persamaan yang digunakan adalah:

1. Energi Manusia (Rahmat, 2002)

$$
\mathbf{E t m}=\frac{(\mathrm{n} \times \mathrm{T} \times \mathrm{Nk})}{J}
$$

Etm $=$ Energi manusia $(\mathrm{MJ} / \mathrm{kg})$

$\mathrm{n} \quad=$ Jumlah tenaga kerja (orang)

$\mathrm{T} \quad=$ Waktu kerja (jam/orang/hari)

$\mathrm{Nk}=$ Nilai kalor manusia (MJ)

$\mathrm{J}=$ Jumlah produksi CPO $(\mathrm{kg} / \mathrm{hari})$

2. Energi Solar (Inayah, 2013)

$$
\mathbf{E b s}=\frac{(\mathrm{n} \times \mathrm{T} \times \mathrm{Nk})}{J}
$$

Ebs= Energi bahan bakar solar $(\mathrm{MJ} / \mathrm{Kg})$

$\mathrm{n}=$ Kebutuhan solar tiap jam (liter/jam)

$\mathrm{T}=$ Waktu kerja alat (jam/hari)

$\mathrm{Nk}=$ Nilai kalor solar $(\mathrm{MJ} /$ liter

$\mathrm{J}=$ jumlah produksi $\mathrm{CPO}(\mathrm{kg} / \mathrm{hari})$ 
3. Energi Listrik (Rahmat, 2002)

$$
\mathbf{E l}=\frac{(\mathbf{P} \times \mathbf{T} \times \mathbf{\eta})}{J}
$$

$\mathrm{El}=$ Energi listrik $(\mathrm{MJ} / \mathrm{kg})$

$\mathrm{P}$ = Daya motor/mesisn terukur $(\mathrm{kw})$

$\mathrm{T}=$ Waktu pemakaian alat (jam)

$\eta \quad=$ Efisiensi teknis alat

$\mathbf{J}=$ Jumlah produksi CPO (kg/hari)

4. Energi Biomassa (Mustikaningsih, 1996)

$$
\mathbf{E b b}=\frac{(\mathrm{JKBB} \times \mathrm{NPB})}{J}
$$

$\mathrm{Ebb}=$ Energi bahan bakar $(\mathrm{kJ})$

JKBB =Jumlah ketersediaan bahan bakar (kg/hari)

NPB =Nilai pembakaran bawah (kJ/kg bahan bakar)

$\mathrm{J}=$ Jumlah produksi CPO (kg/hari)

5. Energi Uap (Fadly, 2003).

$$
\mathbf{E u}=\frac{(\mathbf{M u} \times \mathbf{h s} \times \mathbf{T})}{\boldsymbol{J}}
$$

$$
\begin{aligned}
& \mathrm{Eu}=\text { energi uap }(\mathrm{MJ} / \mathrm{kg}) \\
& \mathrm{Mu}=\text { Laju uap }(\mathrm{kg} / \mathrm{jam}) \\
& \mathrm{Hs}=\text { entalpi uap }(\mathrm{kJ} / \mathrm{kg}) \text { dari tabel } \\
& \mathrm{T}=\text { superheated } \\
& \mathrm{J}=\mathrm{Jum} \text { kerja boiler }(\mathrm{jam})
\end{aligned}
$$

6. Efisiensi Real (Rahmat, 2002)

$$
\text { Eff. } \text { Real }=\frac{U E}{I E} x 100 \%
$$

$\mathrm{UE}=$ Energi berguna $(\mathrm{MJ} / \mathrm{kg})$

Tabel 1. Kebutuhan Energi Primer

\begin{tabular}{lcc}
\hline \multicolumn{1}{c}{ Jenis Energi } & $\begin{array}{c}\text { Pengolahan dan Sarana } \\
\text { Pendukung (MJ/kg) }\end{array}$ & Persentase (\%) \\
\hline Biomassa & 16,02 & 98,88 \\
Solar & 0,179 & 1,10 \\
Manusia & 0,001679 & 0,02 \\
Total & 16,200679 & 100 \\
\hline
\end{tabular}

Sumber : data diolah (2016)

Besarnya kebutuhan energi pada setiap tahapan pengolahan setelah input energi solar dan biomassa pada stasiun penyediaan energi dikonversikan menjadi energi listrik sehingga input yang yang diperhitungkan sudah berupa
$\mathrm{IE}=$ Energi Input $(\mathrm{MJ} / \mathrm{kg})$

\section{Efisiensi Teknis}

Eff.Teknis $=\frac{\text { Kapasitas alat terukur }}{\text { Kapasitas alat terpasang }} \times 100 \%$

\section{HASIL DAN PEMBAHASAN}

Jenis energi yang digunakan pada pengolahan kelapa sawit adalah energi tenaga manusia, energi biomassa, energi solar, energi listrik dan energi uap. Jenis energi ini memiliki sumber energi, energi biomassa bersumber dari cangkang dan serat kelapa sawit, energi listrik bersumber dari biomassa dan solar. Biomassa digunakan sebagai bahan bakar boiler, sehingga menghasilkan uap yang digunakan untuk pengolahan TBS dan pada turbin uap untuk mengubahnya menjadi energi listrik. Energi solar digunakan untuk bahan bakar diesel generator untuk menghasilkan listrik. Energi tenaga manusia bersumber dari tenaga kerja pada pengolahan kelapa sawit dan sarana pendukungnya.

Jumlah kebutuhan energi di PMKS PT. Alno Agro Utama Sumindo Oil Mill, Bengkulu Utara untuk menghasilkan $1 \mathrm{~kg}$ CPO pada kapasitas 60 ton TBS/jam pada dengan rendemen 20,59\% adalah sebesar $16.200679 \mathrm{MJ} / \mathrm{kg}$. Input energi primer terbesar berasal dari energi biomassa sebesar $16,02 \mathrm{MJ} / \mathrm{kg}$ atau $98,88 \%$ dari total masukan energi primer, dengan input energi terkecil berasal dari energi manusia sebesar 0,001679 $\mathrm{MJ} / \mathrm{kg}$ atau $0,02 \%$ dari total masukan energi primer. 
dari energi uap sebesar $7,332 \mathrm{MJ} / \mathrm{kg}$ atau sebesar 99,39\% dari total masukan energi sedangkan input energi terkecil yaitu berasal dari energi manusia sebesar $0,001679 \mathrm{MJ} / \mathrm{kg}$ atau sebesar $0,02 \%$.

Tabel 2. Kebutuhan Energi Final Pengolahan kelapa sawit di PT. Alno Sumindo

\begin{tabular}{lcccc}
\hline \multicolumn{1}{c}{ Jenis Energi } & Pengolahan $(\mathrm{MJ} / \mathrm{kg})$ & $\begin{array}{c}\text { Sarana Pendukung } \\
(\mathrm{MJ} / \mathrm{kg})\end{array}$ & Total $(\mathrm{MJ} / \mathrm{kg})$ & $\begin{array}{c}\text { Persentase } \\
(\%)\end{array}$ \\
\hline Listrik & 0,01678 & 0,0265 & 0,04327 & 0,59 \\
Uap & 6,253 & 1,079 & 7,332 & 99,39 \\
Manusia & 0,000758 & 0,000921 & 0,001679 & 0,02 \\
Total & 6,2705 & 1,1064 & 7,376952 & \\
Persentase (\%) & 85,00 & 15,00 & & 100 \\
\hline
\end{tabular}

Sumber: data diolah (2016)

\section{Energi Manusia}

Energi manusia memiliki peranan penting pada pada pengolahan, terlihat dari penggunaan tenaga manusia pada tiap tahapan pengolahan, mulai dari kegiatan penerimaan buah di loading ramp, pengolahan TBS menjadi CPO, dan kegiatan di sarana pendukung. Total penggunaan energi manusia pada pengolahan TBS menjadi CPO di PMKS PT. Alno Agro Utama Sumindo Oil Mill, Bengkulu Utara adalah sebesar 0,001677 $\mathrm{MJ} / \mathrm{kg}$. Penggunaan energi manusia yang paling besar adalah pada sarana pendukung yaitu sebesar $0,00092 \mathrm{MJ} / \mathrm{kg}$ atau $54,86 \%$ dari persentase total kebutuhan energi manusia. Penggunaan energi manusia yang paling kecil adalah pada pengolahan yaitu sebesar $0,000757 \mathrm{MJ} / \mathrm{kg}$ atau $45,14 \%$ dari persentase total kebutuhan energi manusia. Hal ini disebabkan karena pada sarana pendukung terkhusus work shop menggunakan tenaga manusia sangat banyak berjumlah 19 orang untuk menjaga alat dan mesin peralatan di pabrik dapat langsung diperbaiki jika ada kerusakan dan perawatan.

Tabel 3. Kebutuhan Energi Manusia pada Pengolahan TBS dan Sarana Pendukung

\begin{tabular}{lccc}
\hline \multicolumn{1}{c}{ Kegiatan } & $\begin{array}{c}\text { Kebutuhan Energi } \\
(\mathrm{MJ} / \mathrm{kg})\end{array}$ & $\begin{array}{c}\text { Persentase } \\
\text { Jumlah }(\%)\end{array}$ & Persentase Total (\%) \\
\hline A. Pengolahan TBS & & & 45,14 \\
Penerimaan Buah & 0,000379 & 50,07 & \\
Perebusan & 0,000108 & 14,27 & \\
Penebahan & 0,000054 & 7,13 & \\
Pelumatan & 0,000054 & 7,13 & \\
Pengempaan & 0,000054 & 7,13 & \\
Pemurnian minyak & 0,000108 & 14,27 & \\
Jumlah & 0,000757 & 100 & \\
B. Sarana Pendukung & & & \\
Penyediaan Energi & 0,000244 & 26,52 & \\
Laboratorium & 0,000108 & 11,74 & \\
Penyediaan Air & 0,000054 & 5,87 & \\
Work Shop & 0,000514 & 55,87 & \\
Jumlah & 0,00092 & 100 & \\
Total & 0,001677 & & \\
\hline Sumber: & & & \\
\hline
\end{tabular}

Sumber: data diolah (2016) 


\section{Energi Listrik}

Input energi listrik pada kegiatan pengolahan TBS menjadi CPO dan sarana pendukung di PMKS PT. Alno Agro Utama Sumindo Oil Mill, Bengkulu Utara berasal dari turbin uap dan generator diesel sebesar $0,087 \mathrm{MJ} / \mathrm{kg}$. Sedangkan total kebutuhan energi listrik di PMKS PT. Alno Agro Utama Sumindo Oil Mill, Bengkulu Utara adalah sebesar $0,0434 \mathrm{MJ} / \mathrm{kg}$. Sarana pendukung merupakan bagian yang terbesar dalam mengkebutuhan energi listrik yaitu sebesar $0,0266 \mathrm{MJ} / \mathrm{kg}$ atau $61,25 \%$ dari persentase total kebutuhan energi listrik. Sedangkan bagian pengolahan TBS mengkebutuhan energi listrik sebesar $0,0168 \mathrm{MJ} / \mathrm{kg}$ atau $38,75 \%$ dari persentase total kebutuhan energi listrik. Ada beberapa faktor yang menyebabkan penggunaan energi listrik yang berbeda tergantung dari kondisi peralatan yang digunakan, cara pengoperasian peralatan, dan kapasitas real pengolahan.

Tabel 4. Kebutuhan energi listrik pada pengolahan TBS dan sarana pendukung

\begin{tabular}{lccc}
\hline \multicolumn{1}{c}{ Kegiatan } & $\begin{array}{c}\text { Kebutuhan Energi } \\
(\mathrm{MJ} / \mathrm{kg})\end{array}$ & $\begin{array}{c}\text { Persentase Jumlah } \\
(\%)\end{array}$ & $\begin{array}{c}\text { Persentase Total } \\
(\%)\end{array}$ \\
\hline A. Pengolahan TBS & & & 38,75 \\
Penerimaan Buah & 0,0008 & 4,76 & \\
Perebusan & 0,00009 & 0,54 & \\
Penebahan & 0,00645 & 38,39 & \\
Pelumatan & 0,00122 & 7,26 & \\
Pengempaan & 0,00427 & 25,42 & \\
Pemurnian minyak & 0,00397 & 23,63 & \\
Jumlah & 0,0168 & 100 & \\
B. Sarana Pendukung & & & \\
Penyediaan Energi & 0,013 & 48,95 & \\
Laboratorium & 0,0000226 & 0,09 & \\
Penyediaan Air & 0,0125 & 47,07 & \\
Work Shop & 0,0010 & 3,89 & \\
Jumlah & 0,0266 & 100 & \\
Total & 0,0434 & & \\
\hline
\end{tabular}

Sumber: data diolah (2016)

\section{Energi Bahan Bakar Minyak}

Jenis bahan bakar minyak (BBM) yang digunakan dalam proses pengolahan TBS menjadi CPO adalah solar. Solar digunakan untuk bahan bakar loader di penerimaan buah dan generator diesel pada penyediaan energi. Total penggunaan energi solar di PMK PT. Alno Agro Utama Sumindo Oil Mill, Bengkulu Utara adalah sebesar $0,1784 \mathrm{MJ} / \mathrm{kg}$. Kebutuhan energi solar terbesar terdapat pada penyediaan energi yaitu sebesar $0,145 \mathrm{MJ} / \mathrm{kg}$ atau $81,28 \%$ dari total penggunaan energi solar. Sedangkan tahapan kegiatan yang membutuhan energi solar paling kecil adalah pada penerimaan buah yaitu sebesar 0,0334 $\mathrm{MJ} / \mathrm{kg}$ atau sebesar $18.72 \%$ dari total penggunaan energi solar. Besarnya kebutuhan energi solar pada penyediaan energi karena kebutuhan solar per jam pada disel generator adalah 100 liter. Dimana waktu operasi diesel generator rata-rata adalah 5,4 jam/hari. Sedangkan kebutuhan rata-rata solar pada penerimaan buah atau bahan bakar loader adalah 131 liter/hari. 
Tabel 5. Kebutuhan Energi Solar

\begin{tabular}{lcc}
\hline \multicolumn{1}{c}{ Kegiatan } & Kebutuhan Energi $(\mathrm{MJ} / \mathrm{kg})$ & Persentase $\%$ \\
\hline Penerimaan Buah & 0,0334 & 18,72 \\
Penyediaan Energi & 0,145 & 81,28 \\
Jumlah & 0,1784 & 100 \\
\hline
\end{tabular}

Sumber: data diolah (2016)

\section{Energi Biomassa}

Pada pengolahan TBS menjadi CPO di PMKS PT. Alno Agro Utama Sumindo Oil Mill, Bengkulu Utara, biomassa digunakan sebagai bahan bakar pada ketel uap (boiler). Jenis biomassa yang digunakan adalah ampas dari pengolahan kelapa sawit yaitu berupa serat (fibre) dan cangkang (shell). Rata-rata jumlah serat dan cangkang yang dihasilkan adalah $365870,20 \mathrm{~kg} / \mathrm{hari}$ dengan komposisi yaitu serat sejumlah $258385,723 \mathrm{~kg} / \mathrm{hari}$ dan cangkang sejumlah 107484,48 $\mathrm{kg} / \mathrm{hari}$. Komposisi kedua Biomassa tersebut sebagai bahan bakar ketel uap adalah $70 \%$ serat dan $30 \%$ cangkang.

Nilai kalor serat dan cangkang adalah masing-masing sebesar $10,02 \mathrm{MJ} / \mathrm{kg}$ pada kadar air 34,99\% dan $13,02 \mathrm{MJ} / \mathrm{kg}$ pada kadar air $15,04 \%$. Nilai kalor serat dan cangkang diperoleh dengan menghitung kadar air serat dan cangkang dengan mengoven selama 90 menit. Dari hasil perhitungan didapatkan bahwa masukan energi biomassa adalah sebesar 16,02 MJ/kg dengan komposisi serat 10,40 MJ/kg dan cangkang 5,62 MJ/kg. Kebutuhan biomassa real untuk boiler didasarkan pada pengamatan bahwa semua serat dan cangkang yang dihasilkan digunakan untuk bahan bakar boiler. Dari perhitungan kebutuhan bahan bakar boiler teoritis didapatkan kebutuhan bahan bakar teoritis sebesar 332791,8 kg/hari dengan komposisi serat sejumlah 232954,24 $\mathrm{kg} / \mathrm{hari}$ dan cangkang sejumlah 99837,5 kg/hari. Perbedaan jumlah ketersediaan bahan bakar boiler dengan kebutuhan teoritisnya mengakibatkan adanya sisa bahan bakar biomassa sebesar 33078,43 kg/hari dengan komposisi serat sebesar 23154,90 kg/hari dan cangkang sebesar 9923,53 kg/hari.

Tabel 6. Energi biomassa

\begin{tabular}{lcc}
\hline Jenis biomassa & Energi Biomassa $(\mathrm{MJ} / \mathrm{kg})$ & Persentase $(\%)$ \\
\hline Serat & 10,40 & 64,91 \\
Cangkang & 5,62 & 35,09 \\
Total & 16,02 & 100 \\
\hline
\end{tabular}

Sumber : data diolah (2016)

\section{Energi Uap}

Energi uap sangat diperlukan dalam pengolahan TBS untuk menjaga agar mutu dari CPO sesuai yang diinginkan dan agar proses pengolahan dapat berjalan dengan lancar. Energi uap yang digunakan di PMKS PT. Alno Agro Utama Sumindo Oil Mill, Bengkulu Utara bersumber dari boiler yang mengubah energi biomassa menjadi uap melalui pembakaran dan mengubah air menjadi uap. Selanjutnya uap yang dihasilkan akan digunakan untuk memutar turbin uap untuk menghasilkan energi listrik, sisa energi uap yang digunakan dari turbin ditampung di dalam BPV yang selanjutnya akan didistribusikan ke stasiun pengolahan dan sarana pendukung. Energi uap yang digunakan di PMKS PT. Alno Agro Utama Sumindo Oil Mill, Bengkulu Utara sebesar $7,332 \mathrm{MJ} / \mathrm{kg}$. Penggunaan energi terbesar pada pengolahan TBS sebesar $6,525 \mathrm{MJ} / \mathrm{kg}$ atau 85,28\% dari persentase total penggunaan energi uap. Penggunaan energi terkecil pada sarana pendukung sebesar $1,079 \mathrm{MJ} / \mathrm{kg}$ atau $14,72 \%$ dari persentase total penggunaan energi uap. 
Tabel 1. Penggunaan energi uap

\begin{tabular}{lccc}
\hline \multicolumn{1}{c}{ Kegiatan } & $\begin{array}{c}\text { Kebutuhan Energi } \\
(\mathrm{MJ} / \mathrm{kg})\end{array}$ & Persentase Jumlah (\%) & Persentase Total (\%) \\
\hline A. Pengolahan TBS & & & 85,28 \\
Perebusan & 2,566 & 41,04 & \\
Pelumatan & 0,55 & 8,80 & \\
Pengempaan & 0,55 & 8,80 & \\
Pemurnian Minyak & 1,466 & 23,45 & 14,72 \\
Stroage Tank & 0,504 & 8,06 & \\
Kernel Dryer & 0,616 & 9,85 & \\
Jumlah & 6,252 & & \\
B. Sarana Pendukung & & & \\
Penyediaan Energi & 1,079 & 100 & \\
Jumlah & 1,079 & & \\
Total & 7,331 & & \\
\hline Sul & & & \\
\hline
\end{tabular}

Sumber: data diolah (2016)

\section{Efisiensi Energi}

Masukan energi (IE) paling besar pada boiler berasal dari energi biomassa yaitu sebesar 16,02 $\mathrm{MJ} / \mathrm{kg}$, energi air umpan sebesar $1,079 \mathrm{MJ} / \mathrm{kg}$, energi listrik sebesar 1,3 x $10^{-2} \mathrm{MJ} / \mathrm{kg}$ dan energi manusia sebesar 1,62 $\mathrm{x} 10^{-4} \mathrm{MJ} / \mathrm{kg}$ sehingga total masukan kebutuhan energi pada boiler sebesar $17,112162 \mathrm{MJ} / \mathrm{kg}$. Sedangkan keluaran atau energi berguna (UE) dari boiler berupa uap superheated dengan kandungan energi sebesar $7,819 \mathrm{MJ} / \mathrm{kg}$. Hasil tersebut menunjukan bahwa efisiensi real pengoperasian boiler sebesar $45,69 \%$.

Masukan energi (IE) pada turbin uap berupa uap superheated yang berasal dari boiler sebesar 7,819 MJ/kg. Keluaran atau energi berguna (UE) dari turbin uap yang ditampung di BPV dengan kandungan energi sebesar 7,332 MJ/kg dan energi listrik sebesar $0,085 \mathrm{MJ} / \mathrm{kg}$ sehingga efisiensi real turbin uap untuk menghasilkan listrik yang merupakan perbandingan antara output listrik dan uap yang keluar dari turbin uap dengan input uap superheated dari boiler yaitu sebesar 94,86\%. Efisiensi turbin uap dalam menghasilkan listrik adalah $1,09 \%$ dengan perbandingan output listrik dari turbin sebesar $0,085 \mathrm{MJ} / \mathrm{kg}$ dengan uap superheated yang berasal dari boiler sebesar 7,819 MJ/kg. Sedangkan efisiensi teknis turbin uap sebesar $66,8 \%$. Listrik yang dihasilkan dari turbin uap disalurkan ke alat/mesin di instalasi pengolahan maupun sarana pendukung. Kebutuhan energi pada instalasi pengolahan sebesar $1,68 \times 10^{-2} \mathrm{MJ} / \mathrm{kg}$ sedangkan pada sarana pendukung sebesar $2,65 \times 10^{-2} \mathrm{MJ} / \mathrm{kg}$, sehingga jumlah penggunaan listrik seluruhnya sebesar 4,33 x $10^{-2} \mathrm{MJ} / \mathrm{kg}$. Energi listrik yang dihasilkan dari turbin uap sebesar $0,085 \mathrm{MJ} / \mathrm{kg}$ dan energi listrik yang dihasilkan dari dieselgenerator sebesar $0,002 \mathrm{MJ} / \mathrm{kg}$, sehingga jumlah output listrik sebesar 0,087 $\mathrm{MJ} / \mathrm{kg}$. Efisiensi total penggunaan listrik adalah perbandingan jumlah energi yang di kebutuhan dengan output listrik yang dihasilkan sebesar 49,75\%.

Efisiensi penggunaan uap adalah perbandingan antara penggunaan uap BPV (back pressure vessel) dengan penggunaan uap dari boiler. Penggunaan uap dari boiler sebesar 7,819 MJ/Kg, sedangkan penggunaan uap dari BPV (back pressure vessel) sebesar $7,332 \mathrm{MJ} / \mathrm{kg}$ maka efisiensi penggunaan uap yaitu $93,77 \%$.

Pada diesel generator, input energi berasal dari energi solar sebesar $0,145 \mathrm{MJ} / \mathrm{kg}$ serta tenaga manusia $2,7 \times 10^{-5} \mathrm{MJ} / \mathrm{kg}$ sehingga total masukan energi pada diesel generator sebesar $0,145027 \mathrm{MJ} / \mathrm{kg}$. Sedangkan output yang dihasilkan dari diesel generator tersebut yaitu energi listrik sebesar 0,002 $\mathrm{MJ} / \mathrm{kg}$, sehingga efisiensi real diesel generator yaitu $1,379 \%$ dan efisiensi teknisnya yaitu $47,25 \%$. 
Setiap alat dan mesin peralatan pada pengolahan dan sara pendukung mengkebutuhan energi listrik. Dimana alat dan mesin peralatan yang menggunakan energi listrik memiliki efisiensi teknis motor listrik. Efisiensi teknis motor listrik adalah rata-rata jumlah dari efisiensi teknis motor listrik pada pengolahan dan sarana pendukung sebesar 59,37\%.

\section{Peluang Penghematan Energi}

Pada sarana pendukung penyediaan energi, penggunaan energi biomassa pada boiler terjadi kelebihan serat dan cangkang. Dari hasil perhitungan antara kebutuhan bahan bakar real dengan kebutuhan bahan bakar teoritis untuk boiler (lihat lampiran 4) terdapat selisih pemakaian serat dan cangkang sebesar 33078,43 kg/hari dengan komposisi serat sebesar 23154,90 kg/hari dan cangkang sebesar 9923,53 kg/hari. Apabila serat dan cangkang tersebut dapat disimpan (pemakaian secukupnya tanpa mengurangi uap yang dihasilkan), maka energi yang bisa disimpan dari serat dan cangkang tersebut yaitu sebesar $1,45 \mathrm{MJ} / \mathrm{kg}$. Jika bahan bakar tersebut digunakan untuk mengganti bahan bakar solar, maka dapat menghemat solar sebanyak 77,07 liter/hari.

Pemakaian tenaga manusia pada stasiun-stasiun pengolahan dan sarana pendukung terdapat selisih antara jam kerja normal dan jam kerja real. Besarnya selisih jam kerja normal dan jam kerja real sebesar 3,6 jam/dua shift. Sehingga energi terbuang pada pemakaian tenaga manusia sebesar 0,0004316 MJ/kg.

Penggunaan energi listrik terlihat adanya selisih dari sumber listrik utama (turbin uap dan generator diesel) dengan energi listrik yang terukur pada peralatan pengolahan dan sarana pendukung. Jika dilihat besarnya nilai energi listrik yang dihasilkan dari turbin uap dan generator diesel adalah $0,087 \mathrm{MJ} / \mathrm{kg}$ sedangkan besarnya nilai energi listirk yang terukur pada peralatan dan mesin pengolahan dan saran pendukung adalah $0,04328 \mathrm{MJ} / \mathrm{kg}$. Sehingga terdapat selisih sebesar 0,04372 MJ/kg. Nilai tersebut merupakan energi yang hilang (losses). Kehilangan listrik sebesar 0,04372 MJ/kg atau sebesar 1891,52 kWh.
Energi yang dapat dihemat seperti yang telah diuraikan di atas pada produksi CPO di PMKS PT. Alno Agro Utama Sumindo Oil Mill, Bengkulu Utara adalah sebesar 0,0442 $\mathrm{MJ} / \mathrm{kg}$ dengan uraian energi tenaga manusia sebesar 0,0004316 MJ/kg, energi energi listrik sebesar $0,04372 \mathrm{MJ} / \mathrm{kg}$. Dan energi yang dapat disimpan dari kelebihan energi biomassa untuk bahan bakar boiler adalah $1,45 \mathrm{MJ} / \mathrm{kg}$.

\section{KESIMPULAN}

Jenis energi yang digunakan untuk menghasilkan Crude Palm Oil (CPO) di PMKS PT. Alno Agro Utama Sumindo Oil Mill, Bengkulu Utara adalah energi manusia, energi solar, energi listrik, energi biomassa dan energi uap. Sumber energi biomassa berasal dari cangkang dan serat kelapa sawit, sumber energi listrik berasal dari energi biomassa dan energi solar yang di konversi menjadi energi listrik. Biomassa digunakan sebagai bahan bakar boiler, sehingga menghasilkan uap yang digunakan untuk pengolahan TBS dan pada turbin uap untuk mengubahnya menjadi energi listrik. Energi solar digunakan untuk bahan bakar diesel generator untuk menghasilkan listrik. Energi biologi manusia bersumber dari tenaga kerja pada pengolahan kelapa sawit dan sarana pendukungnya. Jumlah energi primer yang digunakan untuk menghasilkan $1 \mathrm{~kg}$ CPO pada kapasitas 60 ton TBS/jam pada pengolahan kelapa sawit menjadi CPO di PMKS PT. Alno Agro Utama Sumindo Oil Mill, Bengkulu Utara adalah sebesar $16,200679 \mathrm{MJ} / \mathrm{kg}$. Jumlah energi final yang digunakan setelah energi primer biomassa dan solar pada penyediaan energi dikonversi menjadi energi listrik yaitu sebesar 7,376952 $\mathrm{MJ} / \mathrm{kg}$.

Dari aliran energi pada sarana pendukung penyediaan energi didapatkan efisiensi real boiler sebesar 45,69\%, efisiensi real turbin sebesar $94,86 \%$, efisiensi turbin dalam menghasilkan energi listrik sebesar $1,09 \%$, efisiensi teknis turbin sebesar $66,80 \%$, efisiensi teknis generator diesel sebesar $47,25 \%$, efisiensi teknis motor listrik 59,37\%, efisiensi total penggunaan listrik adalah 49,75 $\%$, efisiensi real diesel adalah $1,379 \%$ dan efisiensi penggunaan uap $93,77 \%$. Energi 
yang dapat dihemat di PMKS PT. Alno Agro Utama Sumindo Oil Mill, Bengkulu Utara adalah sebesar $0,0442 \mathrm{MJ} / \mathrm{kg}$ dengan uraian energi tenaga manusia sebesar 0,0004316 $\mathrm{MJ} / \mathrm{kg}$, energi energi listrik sebesar 0,04372 $\mathrm{MJ} / \mathrm{kg}$. Dan energi yang dapat disimpan dari kelebihan energi biomassa untuk bahan bakar boiler adalah 1,45 MJ/kg.

\section{SARAN}

Prosedur operasional standar yang telah ditetapkan harus terus ditegakkan. ditingkatkan Pemeliharaan, perawatan sarana pendukung serta kebersihan pabrik perlu ditingkatkan, sehingga proses pengolahan dapat berjalan efektif dan efisien

\section{DAFTAR PUSTAKA}

Badan Pusat Statistik. 2014. Direktori Perusahaan Perkebunan Kelapa Sawit 2014. Jakarta: Badan Pusat Statistik Indonesia.

Fadly, Muhammad Rizal. 2003. Analisis Energi Pada Pengolahan Kelapa Sawit Menjadi Crude Palm Oil di PKS KWala Sawit PTP. Nusantara II (Persero) Medan-Sumatera Utara. Skripsi. Bogor: Fakultas Teknologi Pertanian, Institut Pertanian Bogor. http://repository.ipb.ac.id/handle/12345 $\underline{6789 / 21765}$. Diakses tanggal 7 Maret 2016

Inayah, Tisah Afiatul. 2013. Analisis Energi Pada Proses Produksi Crude Palm Oil (CPO) di PMKS PT. Condong Garut.Skripsi. Bogor: Fakultas
Teknologi Pertanian, Institut Pertanian Bogor.

http://repository.ipb.ac.id/handle/12345 6789/65820. Diakses tanggal 10 Maret 2016

International Energy Agency. 1987. Source Book For Energy Auditors. edited by M.D. Lyberg. International Energy Agency.

Mustikaningsih, I.S. 1996. Analisis Kebutuhan Energi Pada Proses Pengolahan Kelapa Sawit di PKS Kertajaya, PTPN XI, Banten Selatan. Skripsi. Jurusan Mekanisasi Pertanian. FATETA, IPB. Bogor. http://repository.ipb.ac.id/handle/12345 6789/30664. Diakses tanggal 16 April 2016

Rahmat, Tedi Ali. 2002. Analisis Energi Pada Produksi Crude Palm Oil (CPO) di PTP. Nusantara VII (persero) Unit Usaha Rejosari-Lampung Selatan.Skripsi. Bogor (ID) : Fakultas Teknologi Pertanian, Institut Pertanian Bogor.

http://repository.ipb.ac.id/handle/12345 6789/16240. Diakses tanggal 25 Februari 2016

Wibowo, S. A. 2008. Audit Energi Pada Proses Produksi CPO (Crude Palm Oil) di PMKS PT. Condong Garut Jawa Barat. Skripsi. Fakultas Teknologi Pertanian IPB. Bogor. http://repository.ipb.ac.id/handle/12345 6789/50308. Diakses 24 Mei 2016 